\title{
RESEARCH ON SPEECH SOUNDS FOR THE FIRST SIX MONTHS OF LIFE
}

\author{
BY ORVIS C. IRWIN \\ Univer sity of Iowa
}

Nowhere in the literature of the beginnings of speech during infancy can there be found a systematic and comprehensive account of speech development during the first six months of life. Such accounts as exist are sketchy and for the most part nonconsecutive. The best statements are by Tracy (21), Preyer (15), the Sterns (19), Lewis (13), and Leopold (12). Observations are restricted for the most part to one or two children of the writers themselves. An exhaustive treatment of the literature of the whole range of infancy will not be attempted here. However, a running summary of reports covering speech sounds during the first six months will be presented.

One of the earliest reports on the order of appearance of vowel sounds is that by Löbische (14). As cited by Tracy (21), this order is: $a, e, o, u, i$. Lobische held that the labials $m, b, p$ are the first consonants, an opinion which has cropped up again and again in the literature during the last 90 years. The labials are followed in order by $d, s, g, w, f, c h, k, r, s c h$. Preyer criticizes Löbische's sequence as "going far beyond pure observation." Sigismund (18), according to Tracy, found the vowel sequence to be $a, \ddot{a}, u, e i, o$, $i, \ddot{o}, \ddot{u}, \ddot{a} u, a u$. Schultze (16) held that the vowels ought to appear in the order: $\ddot{A}, A, U, O, E, I, \ddot{O}, \ddot{U}$. Preyer (15) admits that $\ddot{a}$ is one of the first vowels, but criticizes Schultze in considering it invariably the first. Tracy (21) indicated the fact that vowels usually precede consonants and believed that, of the vowels, $a$ (as in calm) with its various shadings is generally the first to appear. He also pointed out that before the sixth month "the primitive vowels are combined with one another and with consonants to produce the first syllabic utterances" (p. 127). In a number of cases the labials $b, p, m$ make their appearance. Sometimes, however, $g$ or $k$ precedes them. $R$ and $l$, which usually are the last to appear, are used by some children quite early. The consonant $m$, which, according to Tracy, is an easy one, combined with the easy vowel $a$, yields the combination ma, which eventuates into mama. "In the case of 
the boy A ... the earliest combination was mam-mam, used in crying." He adds: "In some cases nearly all syllables have been correctly pronounced during the first half year; while in others progress is much slower, very few syllables being certainly mastered before the ninth month" (p. 128).

Tracy's treatment of the subject was rather in the nature of a summary of observations available up to the year 1896. In 1898 Preyer (15) published his two volumes, The mind of the child. The second volume contains an extended account of language development of his own children during the first three years of life and also a valuable appendix summarizing previous work. The following is an outline of the status of speech sounds during the first six months according to Preyer.

Month

\section{Sounds}

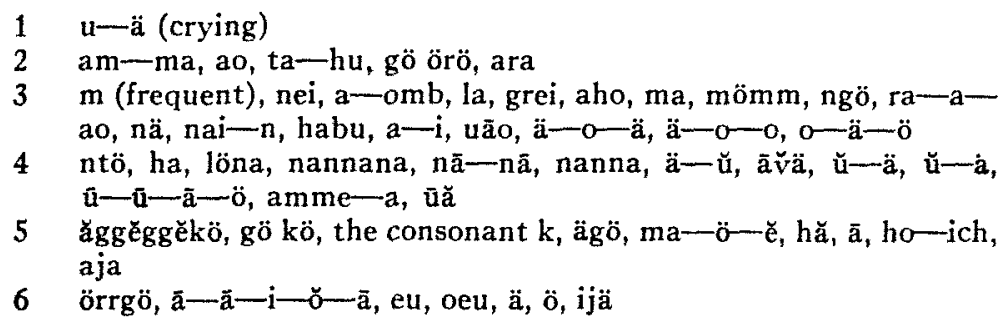

The above outline, however, does not give an adequate picture of Preyer's very extensive work in the field of language development. It does, nevertheless, present a typical variety of vowel and consonant sounds together with their combinations during the first six months. From observations on his own child Preyer found the order of succession to be: $u, \ddot{a}, a, \ddot{o}, o, a i, a o, i, e, \ddot{u}, o e u, a u, o i$. He adds, however, that other children give a varying order.

Die Kindersprache, by Clara and William Stern (19), has for 30 years been considered the outstanding treatise on infant speech. Surprisingly, however, very little original material bearing on development during the first year was collected by them. The few observations during the first six months on their child, Hilda, are:
First few days
ähä
0 years, 1 month, 14 days krä krä
0 years, 2 months, 0 days erre erre
0 years, 2 months, 14 days ekche, ekche

On Gunther the following were found:

First few days 0 years, 2 months

0 years, 5 months ä ähä

$\ddot{a}$ hä, erre

a dadada 
Blanton (1), in 1917, published some observations of the birth cry and of speech sounds during the first month.

The birth cries of different infants were not alike, ranging from simple $a$ (as in at) to $u$ (as in cut). Most of them were compound $u$ (as in cut) followed by $n a h$ (as in at); $u h$ (cut); $n g a$ (at) (p. 458).

Sounds heard during the first 30 days.

Consonant sounds commonly heard are $m$ in conjunction with $a$ as $m a$ (at), $n$ as $n g a$ (nat), $g$ as in $g a h, b$ as in $b a$ (at), $w$ in wäh (at), $r$ as in rah (at), $r$ as in burr, very slight sound, and $y$ as in $y a h$ (at).

Vowel sounds are $o$ as in owl, $e$ as in feel, $o o$ as in pool, $a$ as in an, and $a$ as in father (relatively rare).

Of interest was the variety of animal cries simulated in the nursery. The "pot-rack" of the quail, the cry of the goat, the whine of the pig, and the wail of the wild cat, each had a close imitation (p. 460).

Her curious barnyard theory of infant cries has been echoed by Gesell (7) in his last volume.

Jesperson (11) states:

First, then, come single vowels or vowels with a single consonant preceding them, as $l a, r a, l o$, etc., though a baby's sounds cannot be identified with any of ours or written down with our letters (p. 104).

Babbling or crowing begins not earlier than the third week; it may be, not till the seventh or eighth week. The first sound exercises are to be regarded as muscular exercises pure and simple, as is clear from the fact that deaf mutes amuse themselves with them although they cannot themselves hear them (p. 104).

Concerning consonants he repeats the statement first made by Löbische (14):

All are agreed ... that among the consonants the labials $p, b, m$, are early sounds, if not the earliest (p. 105).

Hoyer and Hoyer (9), in 1924, reported a study on the speech development of their child. The first cries after birth were made on the sound $a$. The following tabulation summarizes the findings of the Hoyers:

Immediately after birth

0 years, 0 months, 11 days

0 years, 0 months, 21 days

0 years, 1 month, 20 days

0 years, 3 months, 0 days

0 years, 4 months, 28 days

0 years, 5 months, 8 days $\breve{a}$

uā, uă

ă, uă, măă

$r, \ddot{\mathrm{g}}$

ma, ä̈̈̈g, ma

$\ddot{\mathbf{g}}$

$b, p, g, m$

Gesell (6), in 1925, reported a study by Malmberg on a complete 24-hour record of the vocal activities of a six-month-old 
child. Sixty-four different sounds were distinguished. The most frequently recurring sound was $d a$ with a frequency of $63 . A$ occurred 46 times; $b a, 30 ; n g w, 21 ; a n a, 15 ; a d a, 13 ; u h, 11$; and the remaining sounds occurred less than 10 times.

Decroly (4) believes that babbling begins toward the end of the second month and overlaps the early period of cries. The first babbling sounds are $e$ and $m$ and especially the gutturals $g, k, r$.

Bühler (2) discusses at length the emotional quality of early cries, but does not explicitly state their phonemic nature, except to say that modifications of the crying sounds can be observed from the second month on.

Whimpering, sighing, and sounds of groaning make their first appearance at the end of the second month. Sounds of displeasure ... can be found ... at the end of the fifth month ... they are phonetically different from other sounds.

Thus, for example, $\mathrm{G} 30: 0: 6$ began to use as a constant sound of displeasure buh and erre erre (p. 38).

Hazlitt (8) claims that the vowels " $a h$ " and " $e h$ " are usually the first sounds and are distinguished even in the crying of the newborn, and repeats the hackneyed expression that the labials $b, p, m$ are early in appearing. The liquid consonants $r, l$ are usually the last to be sounded. She points out that "by about six months children are employing in their babble approximately all the vowels and consonants that enter into the different forms of conventional language" (p. 51).

Shirley (17), in 1933, published the second of her three volumes, In it she suggests that the earliest vocal sound to be recorded among her subjects was a grunt consisting of a rudimentary vowel such as short $u$ or broad $a$, finished by an $n g$. This grunt appeared about the sixth day. She goes on to say that during the first three months syllabic vocalization developed. The earliest syllables were cooings such as boo, goo, hauh, aah, woo, xgsoo, aak, zee, and voh. These appeared at 10 months. Somewhat later the following sounds were heard: ungoo, heuhe, umwah, hu-hu-hui, agoo, elow, and umaah. After the fifth month repetitive speech consisted of: uggle-uggle, erdah-erdah, oddle-doddle, a-bah-bah, hey-hey, bup-bupbup, aduh-duhdeh-duhde-ooh, aduh-ajuh, awooh-awah, and lul-lullah.

In 1938 Lewis's (13) book on Infant speech appeared, and in 1939 Leopold (12) published a valuable account of bilingual development of his daughter.

Since the Sterns (19) wrote their volumes on Die Kinder- 
sprache in 1907, the most ambitious venture in the field has been Lewis's Infant speech. It is a critical and comprehensive summary of the whole literature of the subject. Excellent accounts of the individual studies of the speech of young children are presented in the appendices. His own original contribution consists of data on the linguistic development of his own son. The following represents an adaptation of the outline of this boy's speech sounds during the first six months, presented in Appendix A of the book.

\begin{tabular}{|c|c|}
\hline Age & Sounds \\
\hline 0 months, 14 days & ŭe u $\varepsilon, \varepsilon, a$, uัa, $\mathrm{l} \varepsilon$ \\
\hline 1 month, 10 days & ga \\
\hline $\begin{array}{l}1 \text { month, } 11 \text { to } 13 \\
\text { days }\end{array}$ & le, le, ne, ne, na, ne, ne, na \\
\hline 1 month, 14 days & $\mathbf{g}$ \\
\hline 1 month, 20 days & g \\
\hline 1 month, 27 days & $g$ \\
\hline 2 months, 2 day's & $\varepsilon$, ŭ $\varepsilon, \mathrm{n} \varepsilon, l \varepsilon, \mathrm{j} \varepsilon, \breve{\mathrm{va}}, \mathrm{n} \varepsilon, \mathrm{ja}, \mathrm{ea}, \varepsilon, \mathrm{r}$ \\
\hline 2 months, 6 days & əеə, $น \varepsilon, \varepsilon \ni, x \varepsilon$ \\
\hline 2 months, 10 days & angal, al, ga, $\varepsilon \varepsilon, \mathrm{g} \varepsilon g \varepsilon, \mathrm{g} \varepsilon, \mathrm{gi}, \mathrm{g} \varepsilon \mathrm{l}$ \\
\hline 2 months, 12 days & $\eta \mathrm{g} \hat{\varepsilon}, \hat{\varepsilon} \cap$ \\
\hline 2 months, 20 days & $\varepsilon \varepsilon \varepsilon \varepsilon, \mathrm{g} \varepsilon \mathrm{g} \varepsilon$ \\
\hline 4 months, 2 days & $\varepsilon \varepsilon \varepsilon$ \\
\hline 5 months, 1 day & bub, bub \\
\hline 5 months, 2 days & ppp \\
\hline 5 months, 4 days & bub, bub, pp \\
\hline 5 months, 6 days & bub \\
\hline 5 months, 7 days & ha \\
\hline 5 months, 13 days & $\mathrm{m}, \mathrm{m}, \mathrm{m}$ \\
\hline
\end{tabular}

During the interval of the next two months no transcriptions were made of the child's sounds.

A work of somewhat more limited scope than that by Lewis (13) is Leopold's (12) monograph on Speech development of a bilingual child, published in 1939. It contains transcriptions on the developing speech sounds of a daughter. The emphasis, however, is upon bilingualism. Some observations on a second daughter furnish supplementary material. Leopold reports that during the first weeks the only sounds his daughter produced were cries of dissatisfaction. "The crying consisted of front vowels between [æ] and [a], usually [a]. During the first week it was clearly [aa::], later as a rule simple long [a:]."

Leopold's findings during the first three months are herewith outlined. No sounds for the second quarter are reported.

Month

Sounds

$1 \mathrm{Kx}, \mathrm{R}$, oe, $\Lambda, \mathrm{d}, \mathrm{Il} \mathrm{r} \mathrm{d}, \mathrm{Il} \mathrm{g} \mathrm{d}, \mathrm{l}, \mathrm{h}$ I I d F Ru

$2 \mathrm{uK} \times \mathrm{u}, \mathrm{Eg}$ ə b w, E ə, $\mathrm{A}, \mathrm{u}, \mathrm{v}$ 
In a recent volume Gesell (7) has given a description of the vocal behavior during the first year. Excerpts from this account are given.

Except for crying $\mathrm{h \Lambda}$ (the four-week-old infant) is almost inarticulate. ... His vocalizations are meager and non-expressive, but he mews and makes small throaty noises, precursors of babbling (p. 20).

The 16-week-old infant babbles, coos, chuckles, gurgles and laughs. These are fundamental productions of the oral and respiratory apparatus which will ultimately subserve articulate speech (p. 21).

The barnyard theory reappears in the following quotation:

The 28-week-old infant crows and squeals. At 16 weeks he cooed, at 4 weeks he merely mewed! He has made progress since those small neonatal sounds which emanated from a throat that was used almost exclusively for alimentary purposes.

In the last twelve weeks he has indulged in abundant spontaneous vocalizations, producing vowels, consonants, and even syllables and diphthongs. He is almost ready for defined, duplicated utterance of $m u, m a$, and $d a$, which lead to his first words (p. 23).

There remains for consideration a series of unpublished studies on the status of speech elements during the first six months of life. Curry and Irwin (3) have studied the speech sounds of newborn infants, and Irwin and Krehbiel (10) have transcribed the sounds of 15 babies during the second quarter of the first year. An analysis of over a thousand vowel sounds heard in the cries of 40 newborn infants shows the following distribution:

$\begin{array}{ccc}\text { Vowels } & \begin{array}{c}\text { Frequency } \\ \text { Front }\end{array} & \text { Per Cent } \\ i & & 1 \\ I & & 6 \\ \varepsilon & & 15 \\ \mathfrak{x} & \text { Middle } & 70 \\ \Lambda & & 7\end{array}$

The $x$ sound predominates, and $\varepsilon$ occurs only occasionally. It is interesting to note that an overwhelming majority of these crying sounds are front vowels. Middle vowels are infrequent, and the back vowels $\mathrm{U}, u$ are present in about $1 \%$ of the time. This is apparent from the following tabulation:

$\begin{array}{lc}\text { Vowels } & \text { Per Cent } \\ \text { Front } & 92.0 \\ \text { Middle } & 7.0 \\ \text { Back } & 1.0\end{array}$


Curry and Irwin secured an agreement of $94 \%$ between their observations.

Consonant sounds during the first 10 days of life constitute only a small percentage of sounds. Contrary to reports in the literature the labials $b, p$, and $m$ did not occur. The glottal sound $h$ is the most frequently used consonant, and occasionally $w$ and $k$ are heard.

Irwin and Krehbiel (10) have compared the status of front, middle, and back vowels during the second quarter of the first year of life. The data for the sounds made while crying as well as for those made when not crying are included in the following tabulation:

\begin{tabular}{lcr} 
& \multicolumn{2}{c}{ Month } \\
\multicolumn{3}{c}{ Fourth } \\
\multicolumn{3}{c}{ Front Vowels } \\
Crying & 56.5 & 70.9 \\
Noncrying & 46.5 & 54.6 \\
Middle Vowels \\
Crying & 26.1 & 23.8 \\
Noncrying & 29.2 & 27.0 \\
\multicolumn{3}{c}{ Back Vowels } \\
Crying & 15.5 & 5.5 \\
Noncrying & 23.9 & 18.2
\end{tabular}

An interesting comparison may be made from the data of these two studies. They indicate that, whereas at birth front vowels in the crying of newborns constitute $92 \%$ of the sounds, at the fourth month they represent only $57 \%$ of this class of vowels, and $71 \%$ at six months. Whereas middle vowels constitute $7 \%$ at birth, they have increased to $26 \%$ at four months; and while the back vowels are practically absent at birth, at four months they amount to $16 \%$.

It is difficult to secure an adequate sample of noncrying sounds at birth, but during the second quarter these sounds are increasingly prominent.

Consonants are infrequently used by newborn infants. The glottal $h$, however, is present. During the second quarter of the first year this sound constitutes about $60 \%$ of all consonant sounds uttered. The sound $g$ is used about $20 \%$ of the time. $M, n, b, d, k$, $w, l, j$, and $e$ amount to about $10 \%$, and $t, v, z$, and $f$ are used less than $1 \%$. The remaining consonants rarely occur.

Reliabilities between observers in these two studies are indicated by per cents of agreement well above 90 . 
It will be apparent from this review of the more important studies of infant speech sounds during the first half year of life that there does not exist a large body of data secured from adequate samplings of infants for purposes of a statistical analysis. Most of the observations were taken on one or two children. Usually no systematic research methods were formulated, statistical techniques essential to the analysis of mass data are practically absent, no reliabilities of observers have been established, many observers used an alphabetical rather than a phonetic system of symbols for recording, and most reports indulge in an inordinate amount of interpretation supported by very little empirical material.

\section{BIBLIOGRAPHY}

1. Blanton, M. G. The behavior of the human infant during the first thirty days of life. Psychol. Rev., 1917, 24, 456-483.

2. Buther, C. The first year of life. New York: John Day, 1930.

3. Curry, T., \& Irwin, O. C. Speech sounds of newborn babies. Unpublished study:

4. Decroly, D. Comment l'enfant arrive à parler. Cenirale P. E. S. Belg., 1933, 8, Nos. 1-2, 1-306.

5. Fairbanks, G. Voice and articulation drillbook. Iowa City: Author, 1938.

6. Gesell, A. The mental growth of the preschool child. New York: Macmillan, 1925.

7. Geselt, A., et al. The first five years of life: a guide to the study of the preschool child. (From the Yale Clinic of Child Development.) New York: Harper, 1940.

8. Hazlitt, V. The psychology of infancy. New York: Dutton, 1934.

9. Hoyer, A., \& Hoyer, G. Uber die Lallsprache eines Kindes. Z. angew. Psychol., 1924, 24, 363-384.

10. Irwin, O. C., \& Krenbiel, T. E. Speech sounds during the fourth, fifth, and sixth months of life. Unpublished study.

11. Jesperson, $O$. Language: its nature, development, and origin. New York: Holt, 1928.

12. Leorold, W. F. Speech development of a bilingual child: vocabulary growth in the first two years of growth. Evanston: Northwestern Univ., 1939.

13. LEwis, M. M. Infant speech: a study of the beginnings of language. New York: Harcourt, Brace, 1938.

14. Löвische, I. E. Entwickelungsgeschichte der Seele des Kindes. Wein: Haas, 1851.

15. Preyer, $W$. The mind of the child. Observations concerning the mental development of the human being in the first years of life. Vol. II: The development of the intellect. (Trans. by H. W. Brown.) New York: Appleton, 1898.

16. Schultze, F. Die Sprache des Kindes: eine Anregung zur Erforschung des Gegenstandes. Leipzig: Gunther, 1880.

17. Shirley, M. M. The first two years: II. A study of twenty-five babies. Vol. I: Intellectual development. Minneapolis: Univ. Minnesota Press, 1933. 
18 Sigrsmund, B. Kind und Welt. Braunschweig: Vieweg, 1897.

19. Stern, C., \& Stern, W. Monographien ueber die seelische Entwicklung des Kindes. Vol. I: Die Kindersprache: eine psychologische und sprachttheoretische Untersuchung. Leipzig: Barth, 1907.

20. Stern, W. Psychology of early childhood up to the sixth year of age. (Trans. by A. Barwell from 3rd ed., rev. \& enlarged.) New York: Holt, 1924.

21. Tracy, F. The psychology of childhood. (3rd ed.) Boston: Heath, 1896. 